\title{
Morphological analysis of sigmoid sinus anatomy: clinical applications to neurotological surgery
}

\author{
Kylen Van Osch', Daniel Allen², Bradley Gare², Thomas J. Hudson, Hanif Ladak ${ }^{3+}$ and Sumit K. Agrawal| ${ }^{4 *}$
}

\begin{abstract}
Objectives: The primary objective of this study was to use high-resolution micro-CT images to create accurate three-dimensional (3D) models of several intratemporal structures, and to compare several surgically important dimensions within the temporal bone. The secondary objective was to create a statistical shape model (SSM) of a dominant and non-dominant sigmoid sinus (SS) to provide a template for automated segmentation algorithms.

Methods: A free image processing software, 3D Slicer, was utilized to create three-dimensional reconstructions of the SS, jugular bulb (JB), facial nerve (FN), and external auditory canal (EAC) from micro-CT scans. The models were used to compare several clinically important dimensions between the dominant and nondominant SS. Anatomic variability of the SS was also analyzed using SSMs generated using the Statismo software framework.

Results: Three-dimensional models from 38 temporal bones were generated and analyzed. Right dominance was observed in $74 \%$ of the paired SSs. All distances were significantly shorter on the dominant side $(p<0.05)$, including: EAC - SS (dominant: $13.7 \pm 3.4 \mathrm{~mm}$; non-dominant: $15.3 \pm 2.7 \mathrm{~mm}$ ), FN - SS (dominant: $7.2 \pm 1.8 \mathrm{~mm}$; non-dominant: $8.1 \pm 2.3 \mathrm{~mm}$ ), 2nd genu FN - superior tip of JB (dominant: $8.7 \pm 2.2 \mathrm{~mm}$; non-dominant: $11.2 \pm$ $2.6 \mathrm{~mm}$ ), horizontal distance between the superior tip of JB - descending FN (dominant: $9.5 \pm 2.3 \mathrm{~mm}$; nondominant: $13.2 \pm 3.5 \mathrm{~mm}$ ), and horizontal distance between the FN at the stylomastoid foramen - JB (dominant: $5.4 \pm 2.2 \mathrm{~mm}$; non-dominant: $7.7 \pm 2.1$ ). Analysis of the SSMs indicated that SS morphology is most variable at its junction with the transverse sinus, and least variable at the JB.

Conclusions: This is the first known study to investigate the anatomical variation and relationships of the SS using high resolution scans, 3D models and statistical shape analysis. This analysis seeks to guide neurotological surgical approaches and provide a template for automated segmentation and surgical simulation.
\end{abstract}

Keywords: Sigmoid sinus, Transverse sinus, Jugular bulb - facial nerve, Statistical shape model, Anatomy, Neurotology, Surgical simulation

\section{Introduction}

Temporal bone anatomy involves complicated three-dimensional (3D) relationships between critical structures. The temporal bone contains the middle and inner ear, along with several nerves and vessels, all within a relatively small space. Traditional temporal bone studies involved cadaveric dissection and histopathology [1], but there has

\footnotetext{
* Correspondence: Sumit.Agrawal@|hsc.on.ca

${ }^{\dagger}$ Hanif Ladak and Sumit K. Agrawal contributed equally to this work.

${ }^{4}$ Department of Otolaryngology - Head and Neck Surgery, Western

University, London, Ontario N6A 5C1, Canada

Full list of author information is available at the end of the article
}

been a renewed interest in anatomic analysis with the advent of new imaging techniques [2]. Segmentation of these structures in 3D is important for surgical planning [3], robotic surgery [4], virtual-reality surgical simulation [5-7], and patient-specific cochlear implant programming $[8,9]$. Unfortunately, manual segmentation is very labour intensive, therefore many groups have been working on automating segmentation with polynomial functions [10], atlas-based registration [11], statistical shape models [12-14], and deep learning $[15,16]$. This type of research requires large datasets, and many groups have

(C) The Author(s). 2019 Open Access This article is distributed under the terms of the Creative Commons Attribution 4.0 International License (http://creativecommons.org/licenses/by/4.0/), which permits unrestricted use, distribution, and 
made their datasets publicly available to help the larger research community [17].

The sigmoid sinus (SS) is a paired venous sinus beginning as the continuation of the transverse sinus posteriorly, coursing downward as an S-shaped curve in a groove on the inner surface of the temporal bone. Anteriorly, the horizontal portion of the SS terminates as an enlargement known as the jugular bulb (JB), forming the junction between the SS and internal jugular vein. The location and size of the SS is highly variable, including significant differences between the right and left SS of the same skull due to SS dominance [18-22]. This variation in the position of the SS, as well as its relationships to other structures within the temporal bone, contributes to the complexities of neurotological surgery. Lateral skull-base approaches require a thorough understanding of the relationships between the SS, JB, external auditory canal (EAC), and facial nerve (FN) in order to avoid intraoperative complications.

There have been many cadaveric [18-20, 23-30] and radiologic $[21,22,26,31-36]$ studies investigating the variability of the SS, as well as its anatomic relationships to other structures within the temporal bone. However, the intricacies of temporal bone anatomy can make morphological analysis in two-dimensions (2D) challenging. Generating 3D models from 2D images creates a more realistic representation of the relative temporal bone anatomy. Furthermore, generation of 3D models from numerous specimens permits the analysis of anatomic variability using statistical shape models (SSMs). A SSM is calculated from a database of samples to form a model with a mean shape and several modes of variation [37]. Previous studies have utilized SSMs to study the variability of bony structures [37-42], neurological structures [43], and blood vessels [44-47], however to our knowledge, SSMs have not yet been employed to study SS anatomy.

Virtual reality simulation is an emerging technology in the field of medical education and the anatomic complexities of the temporal bone make surgical simulation an ideal environment to learn lateral skull-base approaches. Current temporal bone simulators aim to reproduce a realistic training environment through the use of 3D displays and virtual tools with haptic feedback [5, 48-51]. However, some simulators lack fine anatomic details, while others offer a limited number of temporal bone templates with which to practice. The next generation of simulators can import computed tomography (CT) scans to allow trainees to practice on patient-specific models [48]. However, manually delineating and segmenting individual structures takes several hours per scan making it impractical for surgical rehearsal. Therefore, automated segmentation of intratemporal anatomy is needed to improve the feasibility of these simulators and SSMs provide a template for these automated segmentation algorithms.

The primary objective of this study was to use highresolution micro-CT images to create accurate 3D models of the SS, JB, EAC, and FN, and to compare several surgically important dimensions within the temporal bone. The secondary objective was to create a SSM of a dominant and non-dominant SS to provide a template for automated segmentation algorithms. Finally, these models will be made publicly available to other researchers on the Auditory Biophysics Laboratory website (abl.uwo.ca).

\section{Methods}

All cadaveric specimens were obtained with permission from the body bequeathal program at Western University, London, Ontario, Canada in accordance with the Anatomy Act of Ontario and Western's Committee for Cadaveric Use in Research (Approval number \#19062014). Micro-CT scans of 38 pathology-free cadaveric temporal bones, from 19 different donors, were utilized. The specimens were scanned using the GE Healthcare eXplore Locus $\mu \mathrm{CT}$ scanner (GE Healthcare, Chicago, IL). The scanner was operated with a voltage of $80 \mathrm{kV}$ and a current of $0.45 \mathrm{~mA}$. Approximately 900 views were captured at an incremental angle of 0.4 degrees. Images were reconstructed with an isometric voxel size of $154 \mu \mathrm{m}$.

3D Slicer v4.6.2 software (http://www.slicer.org) was used to analyze the imaging data [52]. All images were aligned using a series of rigid registration steps. Initially, one master image volume of the right ear was manually rotated into the standard anatomical position mimicking a standard clinical temporal bone CT scan. All left-sided temporal bones were then mirrored to match those of the right side. Subsequent image volumes were aligned to the master volume using a rigid body fiducial registration, with fiducials centered on the following landmarks: cochlear nerve canal, oval window, and round window.

The SS, JB, EAC, and FN were then manually segmented, and 3D models were created. The 3D models of paired SSs were divided into two groups, dominant SS and non-dominant SS, based on relative size. The open source framework, Statismo [53], was used to create the SSMs. The SSMs were made by first creating a gaussian process model from one of the SS models. Then, all the other models were fit to the results and a mean was determined by Statismo. Principal component analysis was then performed. The principal components from the SSMs were utilized to analyze size and shape differences between the dominant and non-dominant SSs, as well as to provide a template for future automatic segmentation.

In 3D Slicer, nine fiducials (F1 - F9) were placed on the $3 \mathrm{D}$ reconstructions of the $\mathrm{SS}, \mathrm{JB}, \mathrm{EAC}$, and $\mathrm{FN}$ to analyze several surgically relevant relationships between 
these structures. Using $\mathrm{x}, \mathrm{y}$, and $\mathrm{z}$ coordinates, five distances between the fiducials were calculated (Fig. 1):

1. The shortest distance between the posterior wall of the EAC and the anterior wall of the SS. The EAC fiducial was placed on the bone immediately adjacent to the EAC skin to incorporate the thickness of the posterior EAC wall.

2. The shortest distance between the descending FN and the anterior wall of the SS.

3. The shortest distance between the 2nd genu of the FN and the superior tip of the JB.

4. The horizontal distance between the descending FN and the superior tip of the JB.

5. The horizontal distance between the FN at the stylomastoid foramen (SMF) and the JB.

All fiducials and segmentations were verified by three authors (KVO, DA, and SKA) to achieve a consensus interpretation. Inter-rater variability was negligible using high-resolution micro-CT scans and well-defined bony landmarks [54].

Statistical analysis was performed using IBM SPSS Statistics for Macintosh, Version 24.0 (SPSS Inc., Chicago, IL, USA). For all values, the means and standard deviations were calculated. The Kolmogorov-Smirnov test was used to test all variables for normality. Paired dominant and non-dominant SS distances were compared using a paired-samples t-test. The $p$ value was set at 0.05 for statistical significance.

\section{Results}

Seventy-four percent of the paired SSs were dominant on the right side. Analysis of the SSMs indicated that SS morphology, regardless of dominance, was most variable at its junction with the transverse sinus, and least variable at the JB (Fig. 2). Comparison of the SSMs revealed that a dominant SS lies more anterior in the temporal bone with a larger and higher JB, compared to a non-dominant SS (Fig. 3).

The dimensional relationships between the SS, JB, EAC, and FN are summarized in Table 1. All distances were significantly shorter in the temporal bone with the dominant SS $(p<0.05)$ (Fig. 4). The distance between the EAC and SS in temporal bones with a dominant SS was $13.7 \pm 3.4 \mathrm{~mm}$, while the distance in temporal bones with a non-dominant SS was $15.3 \pm 2.7 \mathrm{~mm}$. Analysis of the relationship between the FN, SS, and JB revealed the following measurements: shortest distance between descending FN - SS (dominant: $7.2 \pm 1.8 \mathrm{~mm}$; non-dominant: $8.1 \pm 2.3 \mathrm{~mm}$ ), 2nd genu FN - superior tip JB (dominant: $8.7 \pm 2.2 \mathrm{~mm}$; non-dominant: $11.2 \pm 2.6 \mathrm{~mm}$ ), horizontal distance between the descending FN - superior tip JB (dominant: $9.5 \pm 2.3$ $\mathrm{mm}$; non-dominant: $13.2 \pm 3.5 \mathrm{~mm}$ ), and horizontal distance between the FN at the SMF - JB (dominant: $5.4 \pm 2.2$, non-dominant: $7.7 \pm 2.1$ ).

\section{Discussion}

This is the first study to use SSMs to study SS morphology. Thirty-eight 3D models of SSs were utilized to create SSMs of a dominant and non-dominant SS. SSMs are a powerful tool used in the analysis of regional anatomical variability of a structure $[38,41]$. SSMs have previously been employed in skeletal [3742], vascular [44-47], and neurological research [43]. Moreover, recent studies have indicated that SSMs can be a useful tool in pre-operative planning, specifically in bony reconstructions such as in craniomaxillofacial surgeries $[55,56]$. Analysis of the SSMs indicated that

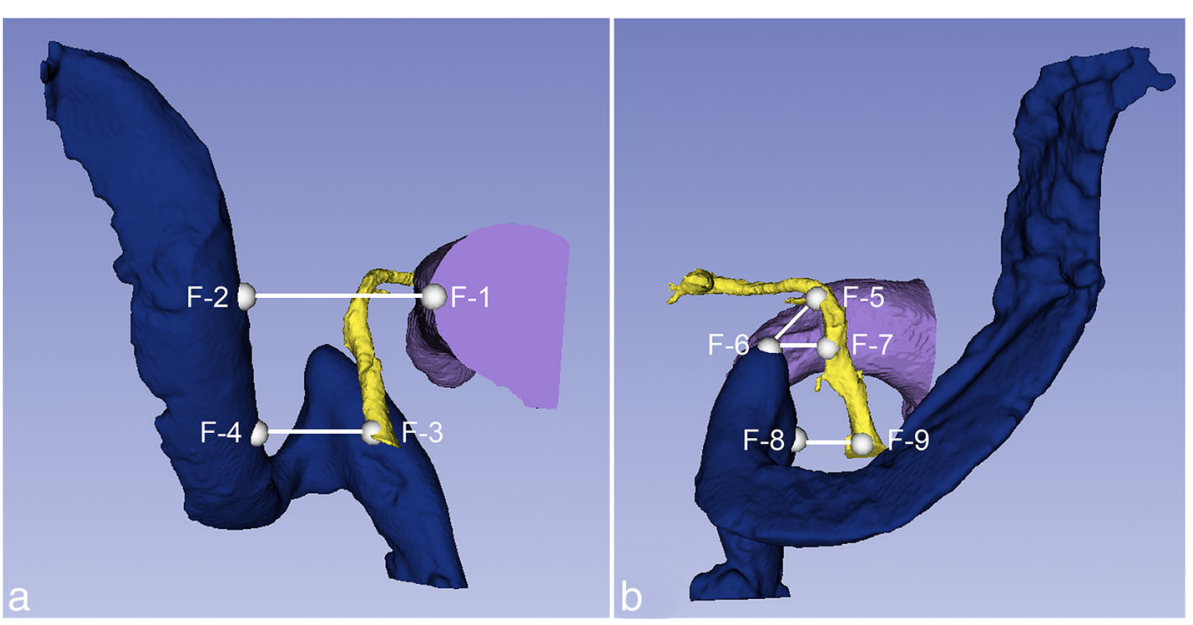

Fig. 1 Fiducials and distances calculated from coordinates (BLUE - SS, YELLOW - FN, PURPLE - EAC). a. EAC - SS (F1 - F2); Descending FN - SS (F3 - F4). b. 2nd genu FN - Superior tip JB. (F5 - F6); Descending FN - Superior tip JB (F6 - F7); FN at the SMF - JB (F8 - F9) 

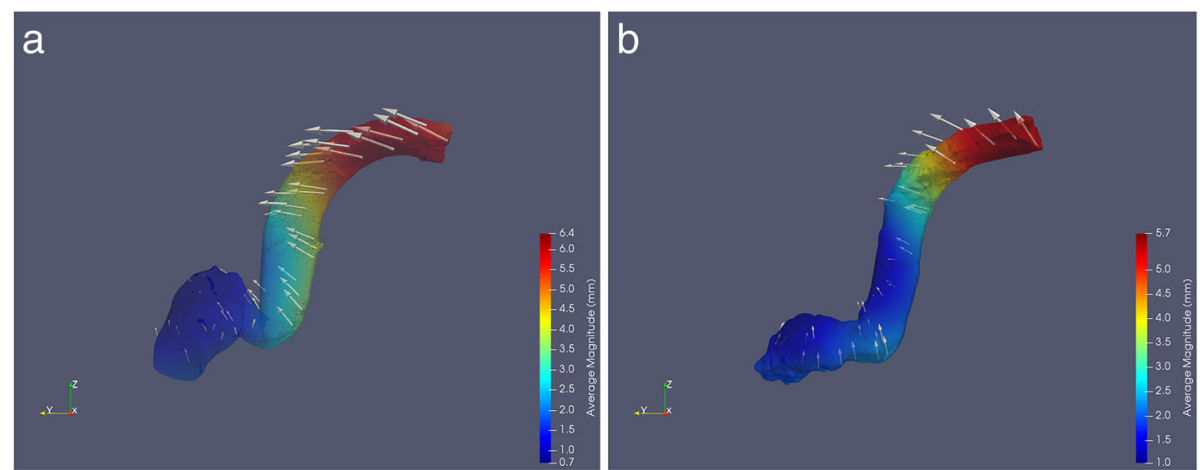

Fig. 2 SSMs and variation of the dominant SS (a) and non-dominant SS (b). Colour mapping portrays magnitude of variation (see legend). Arrows display direction of variation

SS morphology, regardless of dominance, is most variable at its junction with the transverse sinus and least variable at the JB (Fig. 2). When comparing the dominant and non-dominant SSMs (Fig. 3), the dominant SS lies more anterior in the temporal bone with a larger and higher JB, predisposing the dominant SS to an increased risk of intraoperative injury.

The first 3D model of a temporal bone was created by Antunez et al. in 1980 [57]. Since then, technological advancements have allowed the development of more sophisticated 3D models, primarily used for surgical simulation and educational purposes [57-61]. The use of virtual simulation as a surgical educational tool has been increasing [49]. Surgical simulation allows trainees to practice in a standardized and safe environment, allows competence assessment, and avoids the need for cadaveric specimens and related laboratory costs [49]. Concerning neurotology training specifically, the anatomic complexity of the temporal bone makes surgical simulation an ideal environment to learn mastoidectomy, and other lateral skull-base approaches. A recent meta-analysis examining the use of virtual temporal bone surgery simulators found that virtual training improved trainee mastoidectomy performance [49]. Current mastoidectomy simulators aim to reproduce a realistic training environment through $3 \mathrm{D}$ displays and virtual tools with haptic feedback [5, 49-51].

Modern temporal bone simulators such as CardinalSim (Stanford University, CA) [48] can utilize patientspecific imaging for surgical rehearsal. However, manual segmentation of the intratemporal structures is labour intensive and not practical in a clinical setting. Therefore, the 3D models and SSMs created in this study are being used in the development of automated segmentation algorithms. With this technology, virtual patientspecific models can be quickly generated, permitting surgical planning, and allowing trainees to rehearse on a patient's unique temporal bone anatomy and pathology prior to surgery.

The present study also focused on analyzing several anatomic relationships of the SS using $3 \mathrm{D}$ models. Seventy-four percent of the paired specimens revealed
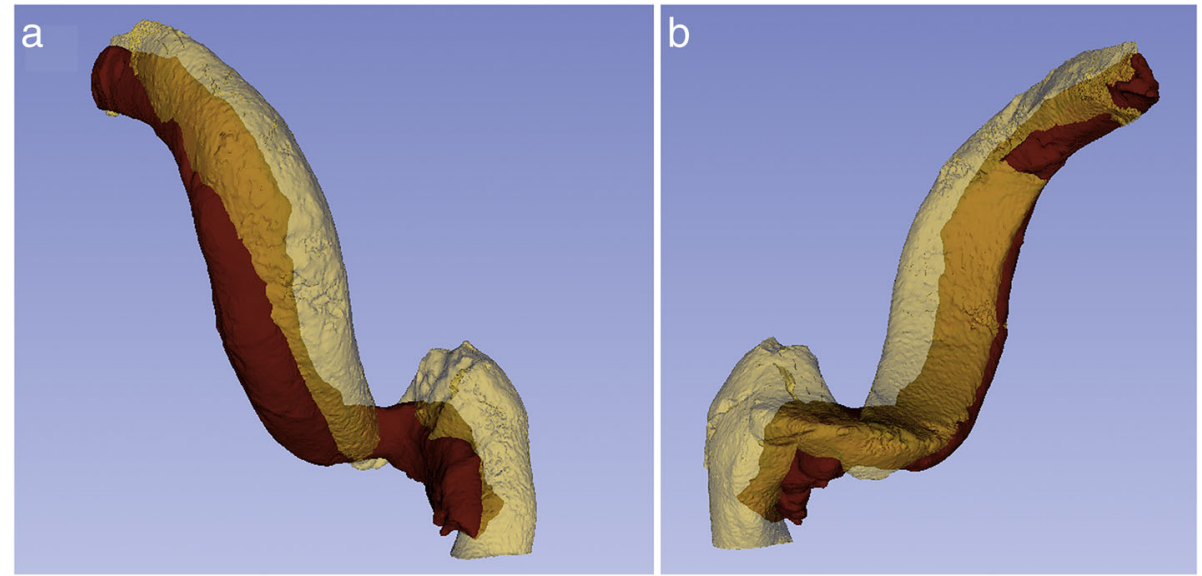

Fig. 3 Comparison of the SSMS of the dominant SS (YELLOW) and non-dominant SS (RED). a. Lateral view. b. Medial view 
Table 1 Comparison of the average distances and ranges between dominant and non-dominant SS

\begin{tabular}{llll}
\hline Parameter & $\begin{array}{l}\text { Dominant SS mean } \\
(\mathrm{mm})[\text { Range }]\end{array}$ & $\begin{array}{l}\text { Non-dominant SS mean } \\
(\mathrm{mm})[\text { Range }]\end{array}$ \\
\hline Shortest distance between the EAC - SS & $13.7 \pm 3.4[6.8-17.7]$ & $15.3 \pm 2.7[11.1-20.6]$ \\
Shortest distance between the descending FN - SS & $7.2 \pm 1.8[3.9-10.7]$ & $8.1 \pm 2.3[3.2-12.1]$ \\
Shortest distance between the 2nd genu FN - superior tip JB & $8.7 \pm 2.2[6.7-14.1]$ & $11.2 \pm 2.6[8.3-18.4]$ & $<0.05$ \\
Horizontal distance between the descending FN - superior tip JB & $9.5 \pm 2.3[6.6-14.3]$ & $13.2 \pm 3.5[6.1-15.5]$ & $<0.05$ \\
Horizontal distance between the FN at the SMF - JB & $5.4 \pm 2.2[1.7-9.3]$ & $7.7 \pm 2.1[3.7-13.4]$ & $<0.01$ \\
\hline
\end{tabular}

SS dominance on the right side. These results coincide with findings in the literature that the SS is frequently larger on the right side $[19,21,22,24]$. The specific distances analyzed in this study were chosen based on those most applicable to neurotologic surgical approaches. Appreciating the shortest distance between the EAC and SS is important for initial drilling into the mastoid bone, in order to avoid accidental injury to the SS. This study found the EAC - SS distance to be significantly shorter in the temporal bone with the dominant SS (dominant: $13.7 \pm 3.4 \mathrm{~mm}$, non-dominant: 15.3 $\pm 2.7 \mathrm{~mm}$ ). The mean EAC - SS distances of the 3D models were similar to previous $\mathrm{CT}$ and cadaveric studies; however, our study found the range of EAC - SS distances was more variable than previously reported (Table 2). The increased variability in this study may be secondary to the relatively large sample size compared with previous studies. In terms of accuracy, this study utilized high resolution micro-CT scans which displayed fine anatomic details. The measurements were also taken in three-dimensions, which allowed determination of the closest relationships between structures compared with the two-dimensional planes used in prior imaging studies.
In this study, several relationships between the SS, JB, and FN were also analyzed. The results reveal that the FN travels significantly closer to the SS and JB in the temporal bone with the dominant SS. Due to the reduced surgical corridor with the dominant SS, care should be taken by trainees to avoid iatrogenic facial nerve injury. In addition, the significant variability in the distances between the SS, EAC, FN, and JB in the specimens, further supports the need for preoperative radiographic review and possible surgical rehearsal [5, 48-51]. A recent study by Cömert et al. (2018), used cadaveric specimens to address knowledge gaps in JB anatomy [30]. Cömert et al. (2018) examined one measurement between the JB and FN. This distance was similar to the analysis of the horizontal distance between the descending FN and the superior tip of the JB in this study. While Cömert et al. (2018) divided their groups based on JB location within the temporal bone, rather than by SS dominance, the overall range of that JB - FN dimension coincides with our study. The present study's additional analysis of the relationship between the SS, JB, and FN further contribute to addressing knowledge gaps in JB anatomy.
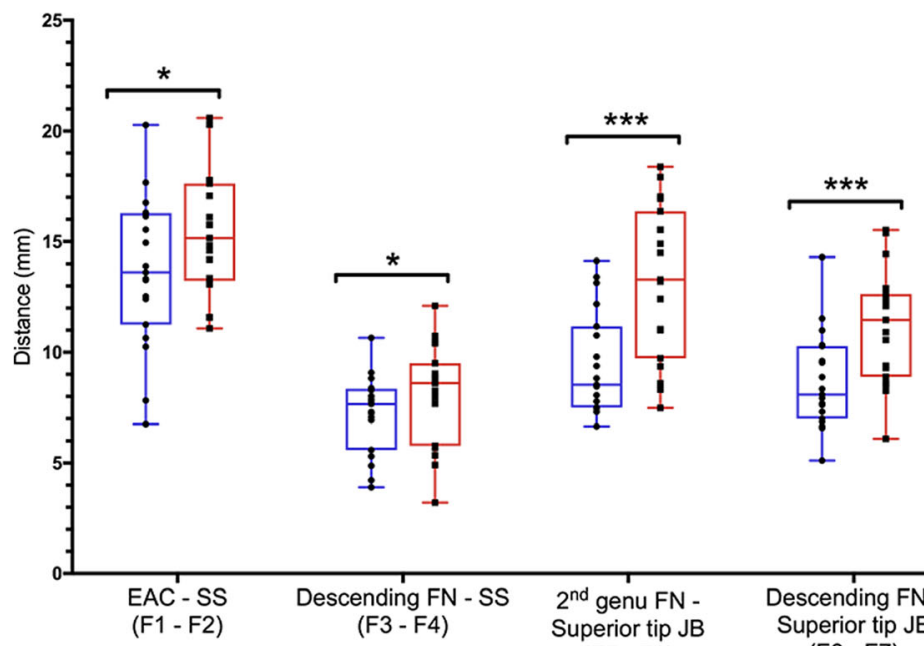

Dominant SS

Non - dominant SS

escending FN - SS $2^{\text {nd }}$ genu FN -

(F5 - F6)

Superior tip JB

(F6 - F7)

Fig. 4 Comparison of the dimensional relationships of dominant and non-dominant SSs. ${ }^{*} p \leq 0.05,{ }^{* * *} p \leq 0.001$ 
Table 2 Comparison of SS - EAC measurements to previous studies

\begin{tabular}{|c|c|c|c|c|}
\hline Study & Method & Mean \pm SD $(\mathrm{mm})$ & Sample Size & Range $(\mathrm{mm})$ \\
\hline Van Osch et al. (2017) & 3D models from $\mu \mathrm{CT}(154 \mu \mathrm{m})$ & $\begin{array}{l}13.7 \pm 3.4 \text { (Dominant SS) } \\
15.3 \pm 2.7 \text { (Non-dominant SS) }\end{array}$ & $\begin{array}{l}19 \\
19\end{array}$ & $\begin{array}{l}6.6-17.7 \\
11.1-20.6\end{array}$ \\
\hline Inal et al. (2015) & $\mathrm{CT}(1.5 \mathrm{~mm})$ & $\begin{array}{l}14.0 \pm 1.2(\text { High JB) } \\
16.5 \pm 2.1 \text { (Low JB) }\end{array}$ & $\begin{array}{l}14 \\
13\end{array}$ & N/A \\
\hline de Melo et al. (2014) & $\mathrm{CT}(1 \mathrm{~mm})$ & $\begin{array}{l}16.1 \text { (Medially displaced SS) } \\
11.1 \text { (Laterally displaced SS) }\end{array}$ & $\begin{array}{l}5 \\
5\end{array}$ & $\begin{array}{l}15.1-17.9 \\
8.8-13.5\end{array}$ \\
\hline Rajati et al. (2013) & Cadaveric & $14.5 \pm 2.9$ & 15 & N/A \\
\hline Wu et al. (2010) & 16-layer helix $C T$ & $13.0 \pm 2.7$ & 238 & $\mathrm{~N} / \mathrm{A}$ \\
\hline Dai et al. (2007) & $\mathrm{CT}(2 \mathrm{~mm} \& 0.75 \mathrm{~mm})$ & $\begin{array}{l}13.9 \pm 2.9 \text { (Right SS) } \\
14.5 \pm 3.2 \text { (Left SS) }\end{array}$ & $\begin{array}{l}58 \\
58\end{array}$ & N/A \\
\hline
\end{tabular}

A limitation of the present study is the failure to consider the sex or size of the skull, as a radiologic study by Dai et al. (2007) has shown significant differences between male and female temporal bones. Sex differences in intratemporal relationships could be explored in future studies. Furthermore, the structures were manually segmented introducing the possibility of subjective error, however the high-resolution micro-CT scans allowed for fairly clear delineation of the anatomic structures.

Previous dimensional analysis of the temporal bone has mainly utilized cadaveric specimens or radiological imaging; however, these studies were limited by dissection expertise, manual measurement, slice thickness, and two-dimensional analysis. Wu et al. [36] utilized multislice CT-multiplanar reformatted images to study relationships within the temporal bone, however resolution was limited by a 16-slice helical CT, precluding the ability to appreciate fine anatomic details. The current study is the first known to use high resolution micro-CT scans, 3D models, and SSMs to analyze SS variability and its relationships within the temporal bone.

Automatic segmentation algorithms are advanced computational models created using micro-CT scan data [17]. These algorithms can then be used to build anatomical models from clinical CT imaging, allowing accurate $3 \mathrm{D}$ reconstruction of a patient's anatomy. Creation of automatic segmentation algorithms requires tedious manual segmentation of micro-CT data, therefore many groups have been working on automating segmentation with polynomial functions [10], atlas-based registration [11], SSMs [12-14], and deep learning [15, 16]. Further, labour intensive manual segmentation often leads to smaller sample sizes. In order to address this, scientific groups are beginning to share their imaging repositories and data analysis. In relation to temporal bone anatomy, a recent study by Gerber et al. (2017), shared their set of imaging, manual delineations, and SSMs of cochlear anatomy. The large sample size and highly detailed models of the SS, JB, EAC, and FN developed for the present study will provide accurate templates for automated segmentation algorithms. Our plan is to further contribute to dataset dissemination by creating a repository of our imaging, 3D models, and data analysis that will be publicly available to other researchers on the Auditory Biophysics Laboratory website (abl.uwo.ca).

\section{Conclusion}

The present study is the first to use 3D models to describe several surgically important dimensional relationships within the temporal bone, as well as the anatomic variability of the sigmoid sinus. Our 3D morphometric analysis seeks to advance understanding of temporal bone anatomy, guide neurotological surgical approaches, and provide models for automatic segmentation and patient specific surgical simulation.

\section{Abbreviations \\ 2D: Two dimensional; 3D: Three dimensional; CT: Computed tomography; EAC: External auditory canal; FN: Facial nerve; JB: Jugular bulb; SS: Sigmoid sinus; SSM: Statistical shape model}

\section{Acknowledgements}

Not applicable.

Funding

Collaborative Heath Research Projects (CHRP).

Availability of data and materials

The datasets used and/or analysed during the current study are available from the corresponding author on reasonable request.

\section{Authors' contributions}

KVO was the primary contributor to the segmentation, measurements, analysis, and manuscript preparation. DA and BG created the statistical shape models and contributed to writing the manuscript. TH performed the facial nerve segmentations. $\mathrm{HL}$ and SKA supervised KVO, DA, BG, and TH. $\mathrm{HL}$ and SKA also conceptualized the project, verified the analysis, and edited the manuscript. All authors read and approved the final manuscript.

Ethics approval and consent to participate

Western University's Committee for Cadaveric Use in Research (Approval number \#19062014)

Competing interests

The authors declare that they have no competing interests.

\section{Publisher's Note}

Springer Nature remains neutral with regard to jurisdictional claims in published maps and institutional affiliations. 


\section{Author details}

'Schulich School of Medicine \& Dentistry, Western University, London, Ontario N6A 5C1, Canada. ${ }^{2}$ Department of Electrical and Computer Engineering, Western University, London, Ontario N6A 5C1, Canada. ${ }^{3}$ Department of Medical Biophysics, Western University, London, Ontario N6A 5C1, Canada. ${ }^{4}$ Department of Otolaryngology - Head and Neck Surgery, Western University, London, Ontario N6A 5C1, Canada.

Received: 24 September 2018 Accepted: 2 January 2019

Published online: 11 January 2019

\section{References}

1. Merchant SN, Schuknecht HF, Rauch SD, McKenna MJ, Adams JC, Wudarsky $\mathrm{R}$, et al. The National Temporal Bone, hearing, and balance pathology resource registry. Arch Otolaryngol Head Neck Surg. 1993;119:846-53.

2. Elfarnawany M, Alam SR, Rohani SA, Zhu N, Agrawal SK, Ladak HM. Micro-CT versus synchrotron radiation phase contrast imaging of human cochlea. J Microsc. 2017;265:349-57.

3. Plontke SK, Radetzki F, Seiwerth I, Herzog M, Brandt S, Delank K-S, et al. Individual computer-assisted 3D planning for surgical placement of a new bone conduction hearing device. Otol Neurotol Off Publ Am Otol Soc Am Neurotol Soc Eur Acad Otol Neurotol. 2014;35:1251-7.

4. Caversaccio M, Gavaghan K, Wimmer W, Williamson T, Ansò J, Mantokoudis $\mathrm{G}$, et al. Robotic cochlear implantation: surgical procedure and first clinical experience. Acta Otolaryngol (Stockh). 2017;137:447-54.

5. Wiet GJ, Stredney D, Kerwin T, Hittle B, Fernandez SA, Abdel-Rasoul M, et al. Virtual temporal bone dissection system: OSU virtual temporal bone system. Laryngoscope. 2012;122:S1-12.

6. Chan S, Li P, Locketz G, Salisbury K, Blevins NH. High-fidelity haptic and visual rendering for patient-specific simulation of temporal bone surgery. Comput Assist Surg Abingdon Engl. 2016;21:85-101.

7. Locketz GD, Lui JT, Chan S, Salisbury K, Dort JC, Youngblood P, et al. Anatomy-specific virtual reality simulation in temporal bone dissection: perceived utility and impact on surgeon confidence. Otolaryngol--Head Neck Surg Off J Am Acad Otolaryngol-Head Neck Surg. 2017:156:1142-9.

8. Jiam NT, Gilbert M, Cooke D, Jiradejvong P, Barrett K, Caldwell M, et al. Association between flat-panel computed tomographic imaging-guided place-pitch mapping and speech and pitch perception in Cochlear implant users. JAMA Otolaryngol--Head Neck Surg. 2018.

9. Rader T, Döge J, Adel Y, Weissgerber T, Baumann U. Place dependent stimulation rates improve pitch perception in cochlear implantees with single-sided deafness. Hear Res. 2016;339:94-103.

10. Pietsch M, Aguirre Dávila L, Erfurt P, Avci E, Lenarz T, Kral A. Spiral form of the human cochlea results from spatial constraints. Sci Rep. 2017:7:7500.

11. Powell KA, Liang T, Hittle B, Stredney D, Kerwin T, Wiet GJ. Atlas-based segmentation of temporal bone anatomy. Int J Comput Assist Radiol Surg. 2017;12:1937-44

12. Reda FA, Noble JH, Rivas A, McRackan TR, Labadie RF, Dawant BM. Automatic segmentation of the facial nerve and chorda tympani in pediatric CT scans. Med Phys. 2011:38:5590-600.

13. Schuman TA, Noble JH, Wright CG, Wanna GB, Dawant B, Labadie RF. Anatomic verification of a novel method for precise intrascalar localization of cochlear implant electrodes in adult temporal bones using clinically available computed tomography. Laryngoscope. 2010;120:2277-83.

14. Kjer HM, Fagertun J, Wimmer W, Gerber N, Vera S, Barazzetti L, et al. Patientspecific estimation of detailed cochlear shape from clinical CT images. Int J Comput Assist Radiol Surg. 2018;13:389-96.

15. Ueda D, Shimazaki A, Miki Y. Technical and clinical overview of deep learning in radiology. Jpn J Radiol. 2018.

16. Sahiner B, Pezeshk A, Hadjiiski LM, Wang X, Drukker K, Cha KH, et al. Deep learning in medical imaging and radiation therapy. Med Phys. 2018.

17. Gerber N, Reyes M, Barazzetti L, Kjer HM, Vera S, Stauber M, et al. A multiscale imaging and modelling dataset of the human inner ear. Sci Data. 2017;4:170132.

18. Sarmiento PB, Eslait FG. Surgical classification of variations in the anatomy of the sigmoid sinus. Otolaryngol--Head Neck Surg Off J Am Acad Otolaryngol-Head Neck Surg. 2004;131:192-9.

19. Kayalioglu G, Gövsa F, Ertürk M, Arisoy Y, Varol T. An anatomical study of the sigmoid sulcus and related structures. Surg Radiol Anat SRA. 1996;18:289-94.

20. Aslan A, Kobayashi T, Diop D, Balyan FR, Russo A, Taibah A. Anatomical relationship between position of the sigmoid sinus and regional mastoid pneumatization. Eur Arch Oto-Rhino-Laryngol Off J Eur Fed Oto-RhinoLaryngol Soc EUFOS Affil Ger Soc Oto-Rhino-Laryngol Head Neck Surg. 1996;253:450-3.

21. Kitamura MAP, Costa LF, Silva DO, Batista LL, Holanda MM, Valença MM. Cranial venous sinus dominance: what to expect? Analysis of 100 cerebral angiographies. Arq Neuropsiquiatr. 2017:75:295-300.

22. Ichijo H, Hosokawa M, Shinkawa H. Differences in size and shape between the right and left sigmoid sinuses. Eur Arch Oto-Rhino-Laryngol Off J Eur Fed Oto-Rhino-Laryngol Soc EUFOS Affil Ger Soc Oto-Rhino-Laryngol Head Neck Surg. 1993;250:297-9.

23. Sennaroglu L, Slattery WH. Petrous anatomy for middle fossa approach. Laryngoscope. 2003;113:332-42.

24. Ramos-Junior SP, Gusmão SN d S, Raso JL, Nicolato AA, Santos M, Caetano IM. Comparative morphometric study of the sigmoid sinus sulcus and the jugular foramen. Arq Neuropsiquiatr. 2014;72:694-8.

25. Tubbs RS, Griessenauer C, Loukas M, Ansari SF, Fritsch MH, Cohen-Gadol AA Trautmann's triangle anatomy with application to posterior transpetrosal and other related skull base procedures. Clin Anat N Y N. 2014;27:994-8.

26. de Melo JO, Klescoski J, Nunes CF, Cabral GAPS, Lapenta MA, Landeiro JA Predicting the presigmoid retrolabyrinthine space using a sigmoid sinus tomography classification: a cadaveric study. Surg Neurol Int. 2014:5:131.

27. Boemo RL, Navarrete ML, Lareo S, Pumarola F, Chamizo J, Perelló E. Anatomical relationship between the position of the sigmoid sinus, tympanic membrane and digastric ridge with the mastoid segment of the facial nerve. Eur Arch Oto-Rhino-Laryngol Off J Eur Fed Oto-RhinoLaryngol Soc EUFOS Affil Ger Soc Oto-Rhino-Laryngol Head Neck Surg. 2008;265:389-92.

28. Kolagi S, Herur A, Ugale M, Manjula R, Mutalik A. Suboccipital retrosigmoid surgical approach for internal auditory canal--a morphometric anatomical study on dry human temporal bones. Indian J Otolaryngol Head Neck Surg Off Publ Assoc Otolaryngol India. 2010;62:372-5.

29. Rajati M, Shahabi A, Haghir H, Afzalaghaee M. The distance of the sigmoid sinus and the middle fossa dura from the external auditory canal in chronic otitis media. Surg Radiol Anat SRA. 2013:35:477-80.

30. Cömert E, Kiliç C, Cömert A. Jugular bulb anatomy for lateral Skull Base approaches. J Craniofac Surg. 2018;29:1969-72.

31. Dai P-D, Zhang H-Q, Wang Z-M, Sha Y, Wang K-Q, Zhang T-Y. Morphological and positional relationships between the sigmoid sinus and the jugular bulb. Surg Radiol Anat SRA. 2007;29:643-51.

32. Aslan A, Goktan C, Okumus M, Tarhan S, Unlu H. Morphometric analysis of anatomical relationships of the facial nerve for mastoid surgery. J Laryngol Otol. 2001;115:447-9.

33. Dai P, Zhang T, Wang K, Song J, Qian W, Wang Z. Positional relationship between the facial nerve and other structures of the temporal bone. $J$ Laryngol Otol. 2004;118:106-11.

34. Tsunoda A, Yamashita K, Matsui M, Komatsuzaki A. Jugular bulb position in the cranial base and its relation to cranial venous system. Nihon Jibiinkoka Gakkai Kaiho. 1992;95:1-6.

35. Inal M, Muluk NB, Dağ E, Arıkan OK, Kara SA. The pitfalls and important distances in temporal bone HRCT of the subjects with high jugular bulbs preliminary report. Adv Clin Exp Med Off Organ Wroclaw Med Univ. 2015; 24:315-24.

36. Wu R-G, Tang B-H, Li L-C, He Y-Q, Huang D-C, Huang H, et al. Measurement of anatomical relationships of facial nerve canal related to middle ear and mastoid surgery on multi-slice computed tomography-multiplanar reformation images. Zhonghua Yi Xue Za Zhi. 2010;90:1551-5.

37. Clogenson M, Duff JM, Luethi M, Levivier M, Meuli R, Baur C, et al. A statistical shape model of the human second cervical vertebra. Int J Comput Assist Radiol Surg. 2015;10:1097-107.

38. Smoger LM, Shelburne KB, Cyr AJ, Rullkoetter PJ, Laz PJ. Statistical shape modeling predicts patellar bone geometry to enable stereo-radiographic kinematic tracking. J Biomech. 2017;58:187-94.

39. Cerveri P, Sacco C, Olgiati G, Manzotti A, Baroni G. 2D/3D reconstruction of the distal femur using statistical shape models addressing personalized surgical instruments in knee arthroplasty: a feasibility analysis. Int J Med Robot Comput Assist Surg MRCAS. 2017.

40. Sarkalkan N, Weinans H, Zadpoor AA. Statistical shape and appearance models of bones. Bone. 2014:60:129-40.

41. Kim S-G, Yi W-J, Hwang S-J, Choi S-C, Lee S-S, Heo M-S, et al. Development of $3 \mathrm{D}$ statistical mandible models for cephalometric measurements. Imaging Sci Dent. 2012;42:175-82. 
42. Melinska AU, Romaszkiewicz P, Wagel J, Antosik B, Sasiadek M, Iskander DR. Statistical shape models of cuboid, navicular and talus bones. J Foot Ankle Res. 2017;10:6.

43. Shen K, Fripp J, Mériaudeau F, Chételat G, Salvado O, Bourgeat $P$, et al. Detecting global and local hippocampal shape changes in Alzheimer's disease using statistical shape models. Neurolmage. 2012;59:2155-66.

44. Medrano-Gracia P, Ormiston J, Webster M, Beier S, Ellis C, Wang C, et al. A study of coronary bifurcation shape in a Normal population. J Cardiovasc Transl Res. 2017;10:82-90.

45. Liang L, Liu M, Martin C, Elefteriades JA, Sun W. A machine learning approach to investigate the relationship between shape features and numerically predicted risk of ascending aortic aneurysm. Biomech Model Mechanobiol. 2017.

46. Bruse JL, McLeod K, Biglino G, Ntsinjana HN, Capelli C, Hsia T-Y, et al. A statistical shape modelling framework to extract 3D shape biomarkers from medical imaging data: assessing arch morphology of repaired coarctation of the aorta. BMC Med Imaging. 2016;16:40.

47. Bruse JL, Giusti G, Baker C, Cervi E, Hsia T-Y, Taylor AM, et al. Statistical shape modeling for Cavopulmonary assist device development: variability of vascular graft geometry and implications for hemodynamics. J Med Devices. 2017;11.

48. Chen C. Homepage [Internet]. CardinalSim. [cited 2018 May 3]. Available from: https://cardinalsim.stanford.edu/

49. Lui JT, Hoy MY. Evaluating the effect of virtual reality temporal bone simulation on Mastoidectomy performance: a meta-analysis. Otolaryngol-Head Neck Surg Off J Am Acad Otolaryngol Head Neck Surg. 2017:156: 1018-24.

50. Leuwer R, Petersik A, Pflesser B, Pommert A, Tolsdorff B, Höhne K-H, et al. VOXEL-MAN TempoSurg a virtual reality temporal bone surgery simulator. J Jpn Soc HEAD NECK Surg. 2008;17:203-7.

51. Sorensen MS, Mosegaard J, Trier P. The visible ear simulator: a public PC application for GPU-accelerated haptic 3D simulation of ear surgery based on the visible ear data. Otol Neurotol Off Publ Am Otol Soc Am Neurotol Soc Eur Acad Otol Neurotol. 2009;30:484-7.

52. Fedorov A, Beichel R, Kalpathy-Cramer J, Finet J, Fillion-Robin J-C, Pujol S, et al. 3D slicer as an image computing platform for the quantitative imaging network. Magn Reson Imaging. 2012:30:1323-41.

53. Lüthi M, Albrecht T, Gass T, Goksel O, Kistler M, Bousleiman H, et al. Statismo - a framework for PCA based statistical models. 2012.

54. Iyaniwura JE, Elfarnawany M, Riyahi-Alam S, Sharma M, Kassam Z, Bureau Y, et al. Intra- and Interobserver variability of Cochlear length measurements in clinical CT. Otol Neurotol Off Publ Am Otol Soc Am Neurotol Soc Eur Acad Otol Neurotol. 2017;38:828-32.

55. Semper-Hogg W, Fuessinger MA, Schwarz S, Ellis E, Cornelius C-P, Probst F, et al. Virtual reconstruction of midface defects using statistical shape models. J Cranio-Maxillo-fac Surg Off Publ Eur Assoc Cranio-Maxillo-fac Surg. 2017:45:461-6

56. Raith S, Wolff S, Steiner T, Modabber A, Weber M, Hölzle F, et al. Planning of mandibular reconstructions based on statistical shape models. Int J Comput Assist Radiol Surg. 2017:12:99-112.

57. Antunez JC, Galey FR, Linthicum FH, McCann GD. Computer-aided and graphic reconstruction of the human endolymphatic duct and sac: a method for comparing Menière's and non-Menière's disease cases. Ann Otol Rhinol Laryngol Suppl. 1980;89:23-32.

58. Wei X-F, Zhang X-Y, Yuan WU, Li Y-S. Accuracy of computer-aided geometric three-dimensional reconstruction of the human petrous bone based on serial unstained celloidin sections. Exp Ther Med. 2015:9:1113-8.

59. Lutz C, Takagi A, Janecka IP, Sando I. Three-dimensional computer reconstruction of a temporal bone. Otolaryngol--Head Neck Surg Off J Am Acad Otolaryngol Head Neck Surg. 1989;101:522-6.

60. Bernardo A, Preul MC, Zabramski JM, Spetzler RF. A three-dimensional interactive virtual dissection model to simulate transpetrous surgical avenues. Neurosurgery. 2003;52:499-505 discussion 504-505.

61. Ahmad N, Wright A. Three-dimensional temporal bone reconstruction from histological sections. J Laryngol Otol. 2014;128:416-20.

Ready to submit your research? Choose BMC and benefit from:

- fast, convenient online submission

- thorough peer review by experienced researchers in your field

- rapid publication on acceptance

- support for research data, including large and complex data types

- gold Open Access which fosters wider collaboration and increased citations

- maximum visibility for your research: over $100 \mathrm{M}$ website views per year

At $\mathrm{BMC}$, research is always in progress.

Learn more biomedcentral.com/submissions 